\title{
Special Considerations for Making Explants and Transplants with Xenopus tropicalis
}

\author{
Marilyn Fisher and Robert M. Grainger ${ }^{1}$ \\ Biology Department, University of Virginia, Charlottesville, Virginia 22904
}

\begin{abstract}
Although Xenopus laevis is an important model organism for embryological experimentation, the smaller, more genetically tractable, and faster developing Xenopus tropicalis provides advantages for using genetic approaches to understand developmental mechanisms. Explant cultures and transplants of $X$. tropicalis embryonic tissues present unique opportunities to examine embryonic tissue determination in a simplified setting. Here we demonstrate preparation of explants and transplants of preplacodal head ectoderm in order to illustrate these approaches; however, these methods apply broadly to tissues throughout the embryo. We focus on technical adjustments to accommodate the differences in size, tissue character, and rate of development between $X$. laevis and $X$. tropicalis. With only modest modifications, $X$. tropicalis embryos are quite amenable to the same kinds of experimental manipulations as X. laevis.
\end{abstract}

It is essential that you consult the appropriate Material Safety Data Sheets and your institution's Environmental Health and Safety Office for proper handling of equipment and hazardous materials used in this protocol.

RECIPES: Please see the end of this protocol for recipes indicated by $<R>$. Additional recipes can be found online at http://cshprotocols.cshlp.org/site/recipes.

Bovine serum albumin (BSA), fraction V $\left(10 \mathrm{mg} / \mathrm{mL}\right.$ stock solution in $\left.\mathrm{H}_{2} \mathrm{O}\right)$

Dilute to $20-100 \mu \mathrm{g} / \mathrm{mL}$ in $1 \times$ MBS for coating dishes and pipettes.

Cysteine- $\mathrm{HCl}\left(2 \%[\mathrm{w} / \mathrm{v}]\right.$ in $\left.\mathrm{H}_{2} \mathrm{O}\right)$

Adjust the $\mathrm{pH}$ to 8.5 using $10 \mathrm{~N} \mathrm{NaOH}$. Alternatively, cysteine free base can be dissolved in $0.1 \times \mathrm{MBS}$ and adjusted to $\mathrm{pH} 8.0$.

Gentamicin $\left(100 \mathrm{mg} / \mathrm{mL}\right.$ in $\mathrm{H}_{2} \mathrm{O}$ )

Dilute the stock solution to a working concentration of $50 \mu \mathrm{g} / \mathrm{mL}$.

Modified Barth's saline (MBS) $<\mathrm{R}>$

Alternatively, Steinberg's solution $(2 x)<R>$ can be used in place of MBS during dissection; see Step 7.

X. tropicalis embryos

A procedure for obtaining embryos via natural matings or in vitro fertilization can be found in Hirsch et al. (2002). $\mathrm{X}$. tropicalis eggs are relatively sticky (compared to X. laevis embryos), both before and after dejellying, and must be handled using coated pipettes and dishes until the hatching stage.

All embryo staging is performed according to Nieuwkoop and Faber (1956).

\footnotetext{
${ }^{1}$ Correspondence: rmg9p@virginia.edu

From the Xenopus collection, edited by Hazel L. Sive.

Supplemental material is available for this article at cshprotocols.cshlp.org.

(C) 2019 Cold Spring Harbor Laboratory Press

Cite this protocol as Cold Spring Harb Protoc; doi:10.1101/pdb.prot097428
} 


\section{Equipment}

Beaker, glass (150-mL)

Cover glasses (optional)

If ectoderm explants are to be maintained as flat sheets (Step 9), they must be immobilized, e.g., under small pieces of glass. To prepare small cover glasses, use a diamond pencil to score and then break small rectangles $(3 \times$ $5 \mathrm{~mm}$ ) from microscope cover glasses. Clean the pieces by washing in alcohol and then allowing to air dry. Store glass pieces in a Petri dish.

To prepare glass bridges to hold transplants in place while healing (Step 15), briefly hold small glass pieces prepared as described above over the flame of a micro Bunsen burner with forceps to fire polish the edges. This will simultaneously cause the glass to curve somewhat, which helps it conform to the shape of the embryo. Alternatively, clay fingers can be used in place of glass bridges; see Step 15.

Dissecting microscope with magnification to $50 \times$

Forceps, blunt-tipped (for immobilizing embryos in clay)

Forceps, fine-tipped (two pairs, for removing membranes from embryos)

Dumont \#5 Biologie-grade forceps are sharper and optimal for delicate manipulations.

Hair tools (for manipulating embryos and tissue pieces without damage)

Prepare eyebrow hairs and/or hair loops fixed into glass capillary tubes with nail polish; see Protocol: Embryo Dissection and Micromanipulation Tools (Sive et al. 2007).

Low-temperature incubator(s) set at $22^{\circ} \mathrm{C}$ and $/$ or $25^{\circ} \mathrm{C}$

Microcapillary tubes for transferring dissected tissues (e.g., 25- $\mu \mathrm{L}$ Drummond Microcaps [Drummond 1-000-0250])

Drummond Microcaps come with convenient bulb dispensers included. Alternatively, a pipette pump (e.g., BelArt SP Scienceware F37898-0000) can be used for controlling flow when glass Pasteur pipettes are used for transferring embryos or tissue pieces. Commercial Pasteur pipettes typically have too wide an opening to be useful for transferring explants from operating dish to culture dish, but they can be narrowed by drawing the ends out after heating delicately over a Bunsen burner flame. Break off the pulled ends of Pasteur pipettes such that the diameter of the openings are only slightly larger than the tissue pieces to be transferred, and fire-polish if necessary.

Operating dishes (clay-lined)

To prepare operating dishes, line the bottoms of 35-mm Petri dishes with clay to a depth of about 1/3. Use clay that is nontoxic, not water-soluble, and is firm enough to hold X. tropicalis embryos and tissues in place (e.g., Claytoon). Prior to use, sterilize the clay dishes with $70 \%$ EtOH and allow to air dry.

Create wells in the clay for securing the embryos during operations using a small glass bulb. To prepare the bulb, draw out the end of a Pasteur pipette over a flame and then hold the drawn-out end over the flame to melt the tip into a ball at the end of the pipette. Control the starting size of the tip and how much of it melts over the flame to form a ball that is roughly the size of an embryo. Once formed, press the glass bulb into the clay to create a well deep enough to almost submerge an embryo. Dishes can be reused after rinsing and sterilization with $70 \% \mathrm{EtOH}$.

Petri dishes

Any dishes used to hold embryos after dejellying must be coated to prevent tissues from sticking to plastic. To coat with $1 \times$ MBS containing $\geq 20 \mu \mathrm{g} / \mathrm{mL} B S A$, add a sufficient volume of solution to completely cover the bottom of the dish, allow to stand for several minutes and then pour off. To coat with a thin layer of agarose $(1 \%[\mathrm{w} / \mathrm{v}] \mathrm{in}$ $0.1 \times M B S)$, pour sufficient melted agarose solution into the dish to cover the bottom and immediately pour off the excess. Allow agarose-coated dishes to dry before using.

Silicone grease (chemical-resistant, heat stable, inert) (Dow-Corning high-vacuum grease)

Transfer pipettes (plastic)

Prior to use, any plastic transfer pipettes that will be used to collect embryos should be coated with $1 \times$ MBS containing $\geq 20 \mu \mathrm{g} / \mathrm{mL}$ BSA. Fill each pipette and expel the solution several times to coat.

Tungsten needles

We use tungsten wire with 0.008 inch diameter (\#214071 from Leico Industries). Needles are electrolytically sharpened using a small plastic beaker of $1 \mathrm{~N} \mathrm{NaOH}$ in which the needle and needle holder complete a circuit using a $6 \mathrm{~V}$ power supply (e.g., see Moore and Kennedy [2008]). We use a modified microscope lamp power supply (for $6 \mathrm{~V}$ lamps); the wires that would normally attach to the bulb are instead attached to alligator clips. One wire is clipped to the metal needle holder into which a piece of tungsten wire is inserted, and the other wire is clipped to the edge of the beaker such that its tip is submerged. The power supply is turned on and the 
M. Fisher and R.M. Grainger

tip of the tungsten wire is submerged in the beaker until the current erodes the tungsten to form a fine tip. Once a good point is obtained on the end of the needle, it helps to use forceps to bend the needle just behind the tip, such that the tip is more parallel than perpendicular with the surface of the embryo when dissection is begun. This allows one to make shallow cuts into the embryo more easily, and prevents damage to the needle tip.

\section{METHOD}

\section{Preparing Tissue Explants}

Here we describe how to prepare explant cultures from preplacodal head ectoderm, specifically the presumptive lens ectoderm (PLE), of embryos from neurula stages 14-21. Supplemental Movie S1 demonstrates PLE dissection from a neurula-stage embryo for explantation. This is not intended to be an exact illustration of a PLE dissection, but rather to illustrate the principal points needed for explant preparation, which can be used as a guide for isolation of tissues from many regions of the embryo. Note that tissues from other germ layers in the early embryo will be far more fragile than the ectoderm, and may require use of tools like an eyebrow knife or glass needle once the ectoderm is removed to allow access to these tissues. Similarly, explants of tissues from other germ layers may be more fragile when cultured directly or placed under glass, and may require higher salt, e.g., $1 \times$ MBS, to maintain tissue integrity during early postoperation phase of culture. Each dissection requires honing the methods used for isolating and maintaining tissues, though the variations described here provide a very good starting point.

\section{Preparing the Embryos}

1. Dejelly $X$. tropicalis embryos by gently swirling them in a small dish or beaker of $2 \%$ cysteine ( $\mathrm{pH}$ 8.5) for $\sim 2.5 \mathrm{~min}$ at room temperature.

Dejellying in a Petri dish allows easy monitoring of the process with a dissecting microscope, so the time needed for complete dejellying can be determined in the context of the specific conditions.

2. When jelly coats have come off, transfer the embryos to a small glass beaker. Rinse the embryos $\sim 10$ times with $30-50 \mathrm{~mL}$ of $0.1 \times$ MBS per rinse.

Thorough removal of cysteine is essential to allow embryos to develop normally.

3. Select embryos at a slightly younger stage than desired and transfer them to a clay-lined operating dish containing $1 \times$ MBS with $20 \mu \mathrm{g} / \mathrm{mL}$ BSA.

The embryos will stick to the clay just enough such that it will be easier to remove the vitelline membranes in Step 4.

Do not prepare too many embryos in advance, as they age fairly rapidly at these stages. The exact rate at which the embryos develop will depend on ambient temperature and their starting stage. A novice should begin with 2 or 3 embryos at a time.

4. Remove the vitelline membranes from the embryos using fine forceps.

This procedure is similar in X. tropicalis and X. laevis embryos, but it is more difficult to see a gap between the membrane and the embryo surface in X. tropicalis, especially before the neurula stages. With either Xenopus species, it is easier to accurately stage embryos with the vitelline envelope removed, since this allows the embryos to reveal subtle morphological features which are otherwise obscured by the constraint of the envelope, and which then generally match the morphologies seen in the Nieuwkoop and Faber (1956) staging series.

\section{Dissecting the PLE}

5. Transfer the demembranated embryos to a fresh clay-lined dish containing $1 \times$ MBS with $20 \mu \mathrm{g} /$ mL BSA for operation. Orient the embryos in wells for PLE dissection: Place the embryos on their sides with the edge between anterior neural tissue and ectoderm (the approximate site of the PLE) facing upward (see Supplemental Movie S1).

Precise illustrations of the PLE site are shown in Jin et al. (2012).

Orientation will vary depending on the piece of tissue being isolated and the age of the donor embryos. 
6. Immobilize the embryos by using blunt forceps to press the clay gently but firmly all around the exposed parts of the embryos to hold them in place (see Supplemental Movie S1). Be sure to also press in gently below the surface level from all sides, such that the clay is touching all sides of the embryos.

The embryos should not be loose in the wells or they will move when manipulated.

7. Dissect the PLE using a tungsten needle and hair loop (see Supplemental Movie S1).

i. Using the needle as if it were a knife, stick the tip down into the tissue (just deep enough to cut through the layer or layers you want to remove) and advance the tip under the tissue in the direction of your outline.

ii. Lift upward, with the tip of the needle leading, and pull the needle up out of the tissue.

iii. Repeat Steps 7.i and 7.ii as many times as necessary until you have completed cutting around the desired piece. (Do not try to cut too much at a time.)

iv. Using a hair loop, gently peel the ectoderm away from underlying mesendoderm and/or neural crest.

$\mathrm{X}$. tropicalis embryos have relatively tough ectoderm compared with X. laevis. At these stages with $\mathrm{X}$. laevis embryos, one can use glass needles for equivalent dissections, or even eyebrow hair tools for younger stage embryos. The tougher $\mathrm{X}$. tropicalis ectoderm is more compatible with the firmness of the tungsten needle, and you will need to exert some force with your needle to cut through the tissue. Lifting cut tissue from its host site can be accomplished with a hair tool, which by being less sharp is also less likely to damage the tissue.

In the case of the PLE, the degree of difficulty of separating the ectoderm from the underlying tissues will increase with the increasing age of embryo and the degree of interaction between the PLE and ultimately the optic vesicle which comes to underlie it. By stage 21, coincidently the age of determination of the PLE (Jin et al. 2012), it can be extremely difficult to separate the ectoderm from the underlying optic vesicle. $2 \times$ Steinberg's solution can be used in place of MBS during dissection to ease tissue separation. See Troubleshooting.

8. Using a BSA-coated glass capillary, carefully transfer the explants from the operating dish to a fresh Petri dish containing $0.5 \times$ MBS with $0.2 \%$ BSA and $50 \mu \mathrm{g} / \mathrm{mL}$ gentamicin.

PLE explants (or any ectoderm) will naturally round up during culture, and $\mathrm{X}$. tropicalis ectoderm is especially prone to this. Depending on your purpose, you may choose to culture the explants as vesicles floating free in the medium or you may hold them as flat sheets under cover glasses. To prepare flat ectoderm explants, immediately transfer the explants to a fresh Petri dish as described and proceed to Step 9.

9. (Optional) To prepare flat ectoderm explants, quickly restrain the individual explants under small cover glasses as follows.

i. Dab a small amount of silicone grease into a clean, empty Petri dish.

ii. Holding the middle of a small cover glass with forceps, carefully apply a very small amount of grease to each end of one side of the cover glass by dipping each end into the grease.

Do not use so much grease that it will spread enough to contact the tissue upon compression in Step 9.iv.

iii. Carefully submerge and move the cover glass into position above an explanted tissue piece.

iv. Carefully lower the cover glass down on top of the explant so that the grease "legs" make contact with the dish, but not the tissue. Very gently press straight down on the cover glass to compress the grease until the glass is lowered just enough to hold the tissue immobile. Do not press too hard or the tissue will disintegrate.

Alternatively, if you do not press hard enough, the tissue will round up and make its way out from under the glass due to the action of the surface cilia.

10. Culture the explants at $22^{\circ} \mathrm{C}-25^{\circ} \mathrm{C}$.

While X. laevis explants (or transplants) are quite tolerant of temperatures between $16^{\circ} \mathrm{C}$ and $25^{\circ} \mathrm{C}$, $\mathrm{X}$. tropicalis are more temperature-sensitive, preferring to be kept within the range of $22^{\circ} \mathrm{C}-25^{\circ} \mathrm{C}$. 


\section{Preparing Transplants}

For some studies it might be desirable to transplant tissues to another embryo, either hetero- or homotopically. In many cases, it is advisable to use host and donor marking to distinguish transplanted tissue from host tissue (e.g., see Jin et al. [2012]). Here the PLE is dissected from a neurula-stage embryo and then transplanted to a neurula-stage host. This procedure is demonstrated in Supplemental Movie S1.

In general, surgical manipulations like the following are performed in $1 \times$ MBS, which promotes tissue healing, but embryos develop more normally in $0.5 \times$ or $0.1 \times M B S$ when the culture period is extended longer than overnight (see Step 17). It is important to note that holding embryos in the relatively high salt $1 \times$ MBS can cause exogastrulation if embryos are being manipulated during gastrula stages.

11. Prepare a clay-lined operating dish as described, using blunt forceps to draw a dividing line across the surface of the clay such that there is a row of wells along either side of the line: one set for donor embryos and one set for hosts.

Wells for the host embryos should be deep enough so that the appropriate site on the embryo surface barely protrudes above the level of the clay surface.

12. Select, prepare and immobilize host and donor embryos in the operating dish containing $1 \times \mathrm{MBS}$ with $20 \mu \mathrm{g} / \mathrm{mL}$ BSA as described in Steps 3-6. Prepare and bury only as many host and donor embryos at one time as can be processed before the embryos age too far.

For the beginner, this may be only one or two sets of embryos.

13. Prepare the host embryo by removing a piece of ectoderm (or other tissue from the region of the body chosen for the transplant site) as described in Step 7. Discard the dissected tissue.

The piece removed should be close in size to the piece you plan to transplant, but it is often valuable to make the host site slightly smaller than the donor tissue since the wound site will often expand slightly from the pressure of holding the embryo in place with clay. If the host site begins to heal, however, it is usually straightforward to open the site slightly by pulling at the corners with a hair tool.

14. Harvest a piece of tissue to be transplanted from the adjacent donor embryo as described in Step 7. Quickly transfer the tissue to the prepared host site using a tungsten needle or hair tool to gently push the tissue piece through the medium into position. Take care not to let the tissue come into contact with the liquid/air interface or it will immediately disintegrate.

15. Place a glass bridge over the transplant so that it is initially above the surface of the transplant site, and then gently press its ends into the clay to hold the transplanted tissue in place.

Alternatively, as shown in Supplemental Movie S1, using fine forceps one can fashion small clay fingers adjacent to the embryo that can be folded over and pressed onto the tissue to hold it in place. The clay fingers take practice to master but are simpler to use in that there is no advance preparation of glass bridges required, and the clay is more easily custom fitted to each individual case. Also, because of the smaller size of X. tropicalis embryos compared with X. laevis, making and working with very small glass bridges can be challenging. An additional benefit of clay fingers is that they will generally not stick to and potentially tear off the transplanted tissue if BSA is included in the operating medium.

16. Allow the transplant to heal for $\sim 15$ min and then lift the clay fingers or glass bridge off the host embryo. Loosen the clay around the host embryos so that subsequent development is not hindered by compression.

17. After 30-60 min of healing in the operating dish, carefully pipette the host embryos into a Petri dish containing $0.5 \times$ MBS with $20 \mu \mathrm{g} / \mathrm{mL}$ BSA. Allow the embryos to develop to the appropriate stage for the experiment.

If it is desirable to keep track of individual host/donor pairs, embryos can be raised in separate wells of 24well plates.

The concentration of $0.5 \times M B S$ is useful because it promotes healing to some degree but does not cause abnormal development as can occur with long culture times in $1 \times$ MBS. Also, we find that this intermediate concentration provides a good transitional level of salt for preventing shock caused by going from an initial dissection in $1 \times M B S$ directly to $0.1 \times M B S$. If the culture period will be longer than overnight, hosts should be transferred to $0.1 \times$ MBS the following day. 
Problem (Step 7): It is difficult to separate the ectoderm from the underlying optic vesicle.

Solution: In such sticky situations, there are a few tricks one can try: (1) Cut around the outline of the tissue to be removed, but wait a couple of minutes before trying to lift off the ectoderm. (2) Chill the embryos briefly (place the dish on ice for a couple of minutes) before making the cuts. Too much chilling, however, will make the ectoderm tear too easily. (3) Switch from $1 \times$ MBS to $2 \times$ Steinberg's saline (since short-term exposure to higher salt media can be helpful for tissue separation). (4) Combine use of Steinberg's saline with option 1 and/or 2. Tissues can also be separated by very mild trypsin treatment (Sigma-Aldrich T8253 or equivalent; free of contaminating proteases), with the exact concentration depending on how strongly tissues are adhering to one another. For the PLE, as an example, from stage 21 onward, $0.001 \%-0.01 \%$ trypsin is sufficient for as long as required for tissue separation, followed by several rinses in soybean trypsin inhibitor (Sigma-Aldrich T9003; typically 0.02\%). Other tissues may require trypsin treatment for clean isolation, e.g., to remove the neural plate from underlying mesoderm.

The techniques described here, although focused on the PLE, apply to any preplacodal head ectoderm as well as to early neural plate/neural tube regions, and with slight modifications, to any embryonic stage. We have used these techniques to prepare PLE explants and transplants for studying aspects of PLE determination in wild-type and transgenic X. laevis (e.g., see Grainger et al. [1988]) and in wildtype, mutant and transgenic X. tropicalis (e.g., see Jin et al. [2012]). The key point is that PLE from both species responds similarly. Although $X$. tropicalis embryos are smaller, require sturdier dissecting tools, and have a narrower tolerance for temperature manipulation, they are well suited to the same types of experimental manipulations as X. laevis and bring to the table advantages for genetic manipulations.

$\mathrm{CaCl}_{2}(0.1 \mathrm{M})$

$11.1 \mathrm{~g} \mathrm{CaCl}_{2}$

Dissolve $11.1 \mathrm{~g} \mathrm{CaCl}_{2}$ in $1 \mathrm{~L} \mathrm{H}_{2} \mathrm{O}$. Autoclave and store in aliquots at $-20^{\circ} \mathrm{C}$ or $4^{\circ} \mathrm{C}$.

MBS Salts (10x)

$\mathrm{NaCl}(880 \mathrm{~mm})$

$\mathrm{KCl}(10 \mathrm{~mm})$

$\mathrm{MgSO}_{4}(10 \mathrm{~mm})$

HEPES (50 mm, pH 7.8)

Omit HEPES if MBS is to be used for oocyte maturation.

$\mathrm{NaHCO}_{3}(25 \mathrm{~mm})$

Adjust $\mathrm{pH}$ to 7.8 with $\mathrm{NaOH}$. Autoclave. Store at room temperature. 
M. Fisher and R.M. Grainger

Modified Barth's Saline (MBS)

$\mathrm{CaCl}_{2}(0.1 \mathrm{~m})$

MBS salts $(10 \times)$

For a $1 \times$ solution of MBS, mix $100 \mathrm{~mL}$ of $10 \times$ MBS salts with $7 \mathrm{~mL}$ of $0.1 \mathrm{M} \mathrm{CaCl}_{2}$. Adjust the volume up to 1 liter with $\mathrm{H}_{2} \mathrm{O}$. Store at room temperature.

Steinberg's Solution $(2 \times)$

\begin{tabular}{|c|c|c|c|}
\hline Reagent & $\begin{array}{l}\text { Quantity needed for } \\
50 \text { mL of stock } \\
\text { solution }\end{array}$ & $\begin{array}{l}\text { Final concentration } \\
\text { of stock solution }\end{array}$ & $\begin{array}{l}\text { Volume of stock solution } \\
\text { needed for } 2 \times \text { Steinberg's } \\
\text { solution }\end{array}$ \\
\hline $\mathrm{NaCl}$ & $8.5 \mathrm{~g}$ & $17 \%$ & $2 \mathrm{~mL}$ \\
\hline $\mathrm{KCl}$ & $0.25 \mathrm{~g}$ & $0.5 \%$ & $1 \mathrm{~mL}$ \\
\hline $\mathrm{Ca}\left(\mathrm{NO}_{3}\right)_{2} \cdot 4 \mathrm{H}_{2} \mathrm{O}$ & $0.4 \mathrm{~g}$ & $0.8 \%$ & $1 \mathrm{~mL}$ \\
\hline $\mathrm{MgSO}_{4} \cdot 7 \mathrm{H}_{2} \mathrm{O}$ & $1.03 \mathrm{~g}$ & $2.05 \%$ & $1 \mathrm{~mL}$ \\
\hline Tris & $2.8 \mathrm{~g}$ & $100 \times$ & $1 \mathrm{~mL}$ \\
\hline
\end{tabular}

Prepare $50 \mathrm{~mL}$ each of $\mathrm{NaCl}, \mathrm{KCl}, \mathrm{Ca}\left(\mathrm{NO}_{3}\right)_{2}, \mathrm{MgSO}_{4}$, and Tris stock solutions in $\mathrm{dH}_{2} \mathrm{O}$, and filter to sterilize. Store stock solutions at room temperature. Before each use, freshly prepare $2 \times$ Steinberg's solution $(50 \mathrm{~mL})$ by combining the volumes of stock solutions listed, adjust the $\mathrm{pH}$ to 7.5 with sterile $1 \mathrm{~N} \mathrm{HCl}$, and then bring to a final volume to $50 \mathrm{~mL}$ with sterile $\mathrm{dH}_{2} \mathrm{O}$.

\section{ACKNOWLEDGMENTS}

Support from the National Institutes of Health (NIH) grants R01 EY006675, R01 EY017400, R01 EY018000, R01 EY022954, and R01 RR013221, as well as from the Sharon Stewart Aniridia Trust and Vision for Tomorrow, is gratefully acknowledged.

\section{REFERENCES}

Grainger RM, Henry JJ, Henderson RA. 1988. Reinvestigation of the role of the optic vesicle in embryonic lens induction. Development 102: 517-526.

Hirsch N, Zimmerman LB, Gray J, Chae J, Curran KL, Fisher M, Ogino H, Grainger RM. 2002. Xenopus tropicalis transgenic lines and their use in the study of embryonic induction. Dev Dyn 225: 522-535. doi:10.1002/ dvdy.10188

Jin H, Fisher M, Grainger RM. 2012. Defining progressive stages in the commitment process leading to embryonic lens formation. Genesis 50: 728-740. doi:10.1002/dvg.22038
Moore SW, Kennedy TE. 2008. Dissection and culture of embryonic spinal commissural neurons. Curr Protoc Neurosci Chapter 3: Unit 3 20. doi:10 $.1002 / 0471142301 . n s 0320 s 45$

Nieuwkoop PD, Faber J. 1956. Normal table of Xenopus laevis. North Holland Publishing, Amsterdam.

Sive HL, Grainger RM, Harland RM. 2007. Embryo dissection and micromanipulation tools. Cold Spring Harb Protoc doi:10.1101/pdb.top7 


\section{Special Considerations for Making Explants and Transplants with Xenopus tropicalis}

Marilyn Fisher and Robert M. Grainger

Cold Spring Harb Protoc; doi: 10.1101/pdb.prot097428 originally published online April 22, 2019

\begin{tabular}{rc}
$\begin{array}{r}\text { Email Alerting } \\
\text { Service }\end{array}$ & Receive free email alerts when new articles cite this article - click here. \\
\hline $\begin{array}{c}\text { Subject } \\
\text { Categories }\end{array}$ & $\begin{array}{c}\text { Browse articles on similar topics from Cold Spring Harbor Protocols. } \\
\text { Developmental Biology (728 articles) } \\
\text { Explant Culture (64 articles) } \\
\text { Xenopus (210 articles) } \\
\text { Xenopus Transgenics (32 articles) }\end{array}$ \\
\hline
\end{tabular}

